\title{
USE OF FORCE TRACKING SYSTEMS DURING NATURAL CATASTROPHES
}

\author{
Marko Pavlović and Bojan Cvijanović \\ Ministry of Defence of Bosnia and Herzegovina
}

The flood that engulfed Bosnia and Herzegovina, the Republic of Serbia and the Republic of Croatia in 2014 imposed a need to establish a more efficient system of command and control over involved units and departments. The complexity of the situation, as well as the composition and cooperation between various forces in the field gave rise to consider the applying of modern systems of command and control. The paper presents the basic characteristics of modern information system of command and control that are currently in use in the armed forces and civilian power structures of developed countries. Using historical method and the chronology is seen development of Blue Force Tracking, Tactical Ground Reporting i GeoSuite systems. By analyzing and comparing these systems we have come to conclusions on their advantages and disadvantages. At the end, there are the suggestions for the development of its own system.

Key words: natural catastrophes, command and control, Blue Force Tracking, Tactical Ground Reporting System, force tracking systems and system GeoSuite

\section{Introduction}

Natural and other catastrophes and accidents, by the damage they do and casualties they cause are a big threat to the security of a state. One of the tasks of modern armed forces worldwide is to assist civil authorities in responding to natural and other catastrophes and accidents, ${ }^{1}$ or providing assistance in cases of large-scale natural disasters, in which human lives, environment and material goods are endangered ${ }^{2}$. When implementing this, task units of the armed forces on the ground cooperate with the forces of civil authorities (civil defense, police, rescues services, and so on) as well as the specialized units of foreign countries. Directing and coordination of all these elements in the field is difficult because of the different organizations of the same, but also because of the specifics of the task.

The system of command and control allows commanders and leaders to execute assigned mission and tasks and, in the same time, enables them to get an insight into the situation and capabilities of subordinates. The success of the work of commands, among other things, to a large extent depends on the knowledge status and their own units'

\footnotetext{
${ }^{1}$ Law on Defense of Bosnia and Herzegovina, Sarajevo, 15 October 2005, article 4), p. 1.

${ }^{2}$ Defence Strategy of the Republic of Serbia, Belgrade, October 2009, p. 15.
} 
disposition. This is achieved by the control, i.e. through its key elements: information, communication and structure. Effective communication is the basis of achieving effective command and control. Communication allows for the delivery and sharing of information within the structure. The information flows vertically (within the chain of command) and horizontally (among subordinate, adjacent, supporting, and supported units). ${ }^{3}$

Particular contribution in these situations provides geospatial intelligence elements. Geospatial intelligence provides a wide spectrum of support to decision makers and units on the field, ranging from the estimate of the situation on the ground, assessment of weather and soil conditions, to monitoring and coordination of the activities of armed forces and civilian authorities units. Geographic information systems, systems for monitoring troops on the ground and various types of simulations that were until recently the privilege of the armed forces in combat, nowadays may find its use during emergencies.

On the other hand, some of the commercial technologies were used for increasing the operational efficiency of the US Army at the beginning of XXI century. The aim was to enable the sharing of information and improve cooperation between units at the tactical level that had a need for updated information by superiors and neighboring units with the aim to enable them to successfully complete its task. This concept is called "edgeenabled system". It is designed for users who do not have access to "thick-client terminal", which are actually the soldiers on the ground.

In this way the soldiers in the field have been given access to relevant information, but also the obligation to collect them and report on them. They are collectors and users of information. In this system, the data is not necessarily tied to any device or platform, but they can be accessed from any device that is connected to the system, so called "cloud storage". Also, the system can be adjusted by offering different configurations, settings, applications or themes so that it can respond to different needs. Thus, similar to the "smart" phones that use the Android or similar operating system. US Army conducted the adaptation of new systems for its own needs, and to enable better horizontal and vertical communication through the system of command and control.

Soldiers in war environment face rapidly changing, highly flexible and everywhere present enemy. Decentralization of the chain of command is essential for performing the tasks which focus on the mission, and these systems are coming to meet their needs. ${ }^{4}$ The situation is similar with a variety of services that are involved in emergency situations such as natural disasters.

\section{Blue Force Tracking - BFT}

In the late eighties and early nineties of the last century there has been a rapid development in the field of computer science. Innovation and continuous improvement of software and hardware caused huge changes in the World over the last three decades. The armed forces of

\footnotetext{
${ }^{3}$ FM 6-0, Mission Command: Command and Control of Army Forces, US Army Training and Doctrine Command, august 2003, chapter 3.

${ }^{4}$ Cerdec's work in developing, assessing and adapting hand-held solutions and commercial applications for the battlefield, August 25, 2010, Washington, DC, Department of Defense, visited the day: 14 March 2015, http://www.defense.gov/Blog_files/Blog_assets/20100825_anthony_transcript.pdf.
} 
the United States took advantage of advances of this technology. Based on the experience of the Gulf War ${ }^{5}$ they decided to carry out the integration of this computer technology into their units.

US Army began work on the program $\mathrm{FBCB}^{6}{ }^{1}$ in 1994, along with the institutional and operational reorganization. ${ }^{7}$ Development of Global Positioning System (GPS) during the penultimate decade of the twentieth century, has allowed commanders and soldiers at all levels of command, accurate and timely information about their position in space. They immediately recognized the significance of information about the locations of subordinate commanders, neighbor and opponent units. The aim was to create a command and information network system that will enable the units on the battlefield to get situational awareness in real time on the issues: disposition of friendly and enemy forces presented on operational maps and graphs, as well as orders and requests from the command and control chain.

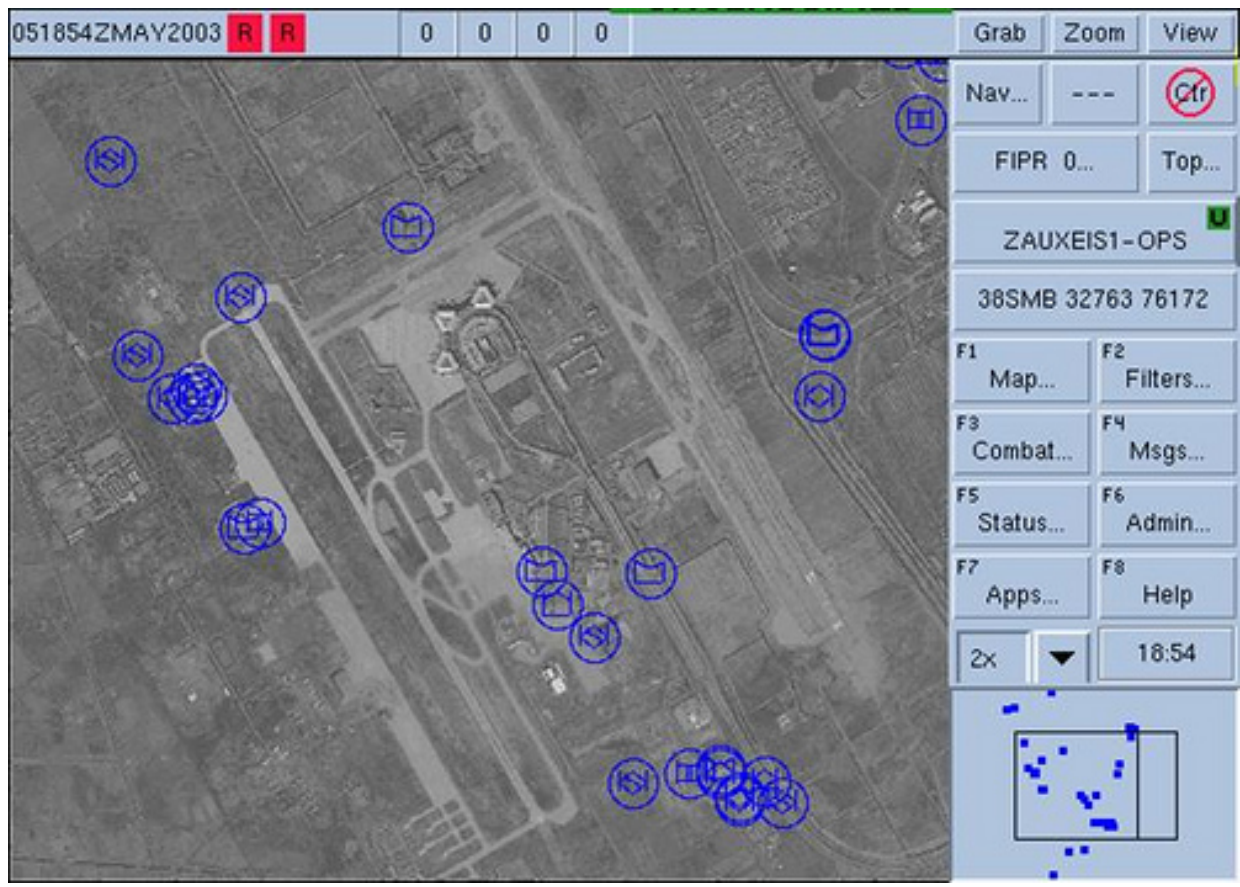

Fig. 1 - BFT interface

FBCB2 used GPS transceivers that are located primarily in the brigade and lower levels mobile command posts. Information about units' location has been delivered to other units via radio network - Combat Net Radios. Locations of vehicles are displayed on a digital map which

\footnotetext{
${ }^{5}$ Sand storms disabled accurate location determination and discerning between friendly and enemy elements.

${ }^{6}$ Digital command system Force XXI Battle Command Brigade and Below (FBCB2).

${ }^{7}$ James L. Conatser, Vincent E. Grizio, Force XXI Battle Command Brigade and Below-Blue Force Tracking (FBCB2-BFT), Naval Postgraduate School, Monterey, California, December 2005.
} 
is set in computers in vehicles. ${ }^{8}$ Also, the soldiers were able to find in their maps information about the enemy (that update intelligence authorities), the operational borders and restricted areas. FBCB2 enabled sending text messages, orders and requests for combat support. ${ }^{9}$

When the Army deployed to the Balkans, however, it discovered that the mountainous terrain and relatively thinly deployed patrol vehicles in Bosnia and Kosovo imposed significant limitations on a tactical internet using ground-based line-of-sight radios. To overcome this, FBCB2 was adapted to communicate over commercial satellites using transceivers bolted to the tops of vehicles. This configuration came to be known as "FBCB2-Blue Force Tracking" or "FBCB2-BFT" ${ }^{10}$ (commonly called "BFT") to distinguish it from the original FBCB2. The Army units equipped with BFT were able to answer the three critical questions - "Where am I? Where are my forces? Where is the enemy?" - with previously impossible speed and accuracy, even when spread over vast distances. ${ }^{11}$

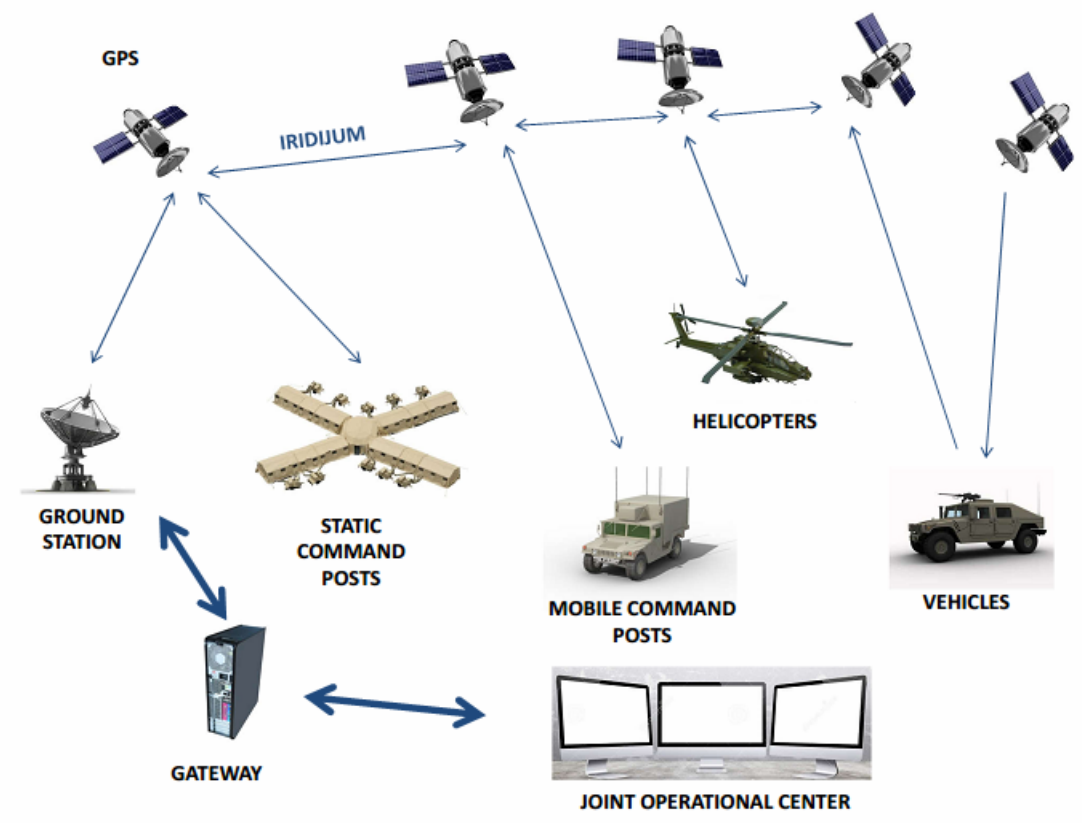

Fig. 2 - Diagram of the system BFT

\footnotetext{
${ }^{8}$ Richard J. Dunn III, "Blue Force Tracking, The Afghanistan and Iraq Experience and Its Implications for the U.S. Army", Northrupp Grumman Mission Systems, 2005, p.4.

${ }^{9}$ Richard J. Dunn III, "Blue Force Tracking, The Afghanistan and Iraq Experience and Its Implications for the U.S. Army", Northrupp Grumman Mission Systems, 2005, p.4.

${ }^{10}$ Force XXI Battle Command Brigade and Below (FBCB2) Blue Force Tracker (BFT).

${ }^{11}$ Richard J. Dunn III, "Blue Force Tracking, The Afghanistan and Iraq Experience and Its Implications for the U.S. Army", Northrupp Grumman Mission Systems, 2005, p.7.
} 
FBCB2 JCR/BFT2 ${ }^{12}$ is enhanced by technology FBCB2/BFT which enables interoperability between the US Army and the US Marine Corps. FBCB2/BFT came into use among the units that are in Afghanistan in October 2012. Improvements include renewed hardware and software; the more improved and faster satellite connection and additional security devices for communications and cryptographic data protection. ${ }^{13}$ It is used to send information and notification by the brigade unit level toward subordinated elements and to exchange data about location and direction of movement between the elements in combat with the aim of synchronizing operations and reducing fratricide.

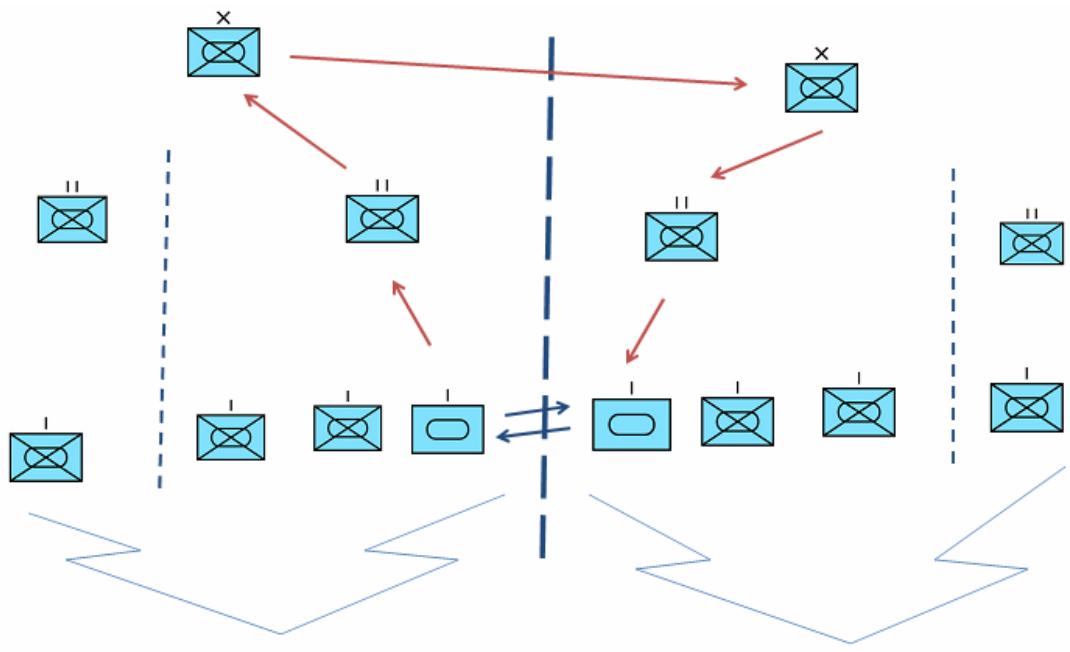

Legend:

$\longrightarrow$ Flank Unit Cross Zone Coordination without BFT

$\longrightarrow$ Flank Unit Cross Zone Coordination with BFT

Fig. 3 - Cross Brigade Zone of Attack Coordination ${ }^{14}$

The good sides of the BFT:

- It allows commanders quickly, accurately and very effective command and control of subordinate, but also cooperation between neighboring units in the field.

- Cooperation between units is increased (fig. 2). Commanders and leaders at all levels command have the same access to information via computer and they know where theirs superior and subordinated units are at any moment.

\footnotetext{
${ }^{12}$ Force XXI Battle Command Brigade and Below (FBCB2) Joint Capabilities Release (JCR) Blue Force Tracker 2 (BFT2).

${ }^{13}$ Nancy Jones-Bonbrest, "Situational Awareness for a Digital Generation", Armor \& Mobility, November 2013, Tactical Defense Media, Inc. Silver Spring, MD, p.3-4.

${ }^{14}$ Richard J. Dunn III, "Blue Force Tracking, The Afghanistan and Iraq Experience and Its Implications for the U.S. Army", Northrupp Grumman Mission Systems, 2005, p.10 (Figure 2: Cross Brigade Zone of Attack Coordination).
} 
- Commanders can issue immediate orders to fire and logistical support to subordinate units due to accurate knowledge of the location of subordinates and enemy units.

- Avoiding of fratricide. Although there are systems to identify enemy vehicles ${ }^{15}$ and units, BFT has a significant role to avoid friendly fire. ${ }^{16}$

- All of the above increases self-confidence and strengthens trust between units in the field and their leaders.

Disadvantages of BFT are:

- Inability to update the location of enemy forces by units in the field.

- Disabled intelligence databases access due to the security of classified information. This disables the creation of accurate and timely picture of the opponent's positions and intentions.

- Lack of tools for planning and monitoring achieved in regard to planned.

- Necessity of increasing the flow of data through satellite communications.

- Inability to support the lowest infantry tactical elements in counterterrorism and insurgent activities. (The system works only in vehicles. There is no possibility that would be carried by the infantry dismounted warfighters.)

- Errors in determining the location on the ground and temporary errors.

It is anticipated that the JBC- $\mathrm{P}^{17}$ replace JCR during 2014. The new platform allows communication between infantry units, vehicles, aircraft and senior staffs by exchanging voice, data and image over large distances. The new interface is based on the experiences of soldiers from the battlefield. JBC-P includes ASCOPE ${ }^{18}$ option that allows commanders planning operations, estimate of the situation and risk mitigation. Perhaps the most important is to enable the exchange and use of data from the Tactical Ground Reporting System. Teams and platoon leaders get mobile network device that connects to the system via the Network Services Gateway (NSG). NSG uses Internet protocol (IP) interface. Mobile devices are connected to the network via the radio device. With this, commanders on the command posts have knowledge of the disposition of their dismounted soldiers on the ground. Also, except of the command, this enables control of subordinated unites.

\section{Tactical Ground Reporting system - TiGR}

Tactical Ground Reporting (TiGR) is an information-centric system that enables users to collect, share and analyze data using a Google Earth like interface. It was developed by C4 Systems General Dynamics. The research project was sponsored by the Defense Advanced Research Projects Agency (DARPA). It was developed in line with needs of leaders operating at company and below levels in order to increase combat effectiveness across the full

\footnotetext{
${ }^{15}$ e.g.: Recognition of Combat Vehicles (ROC-V). More about ROC-V: John O'Connor and Christina Bates, "Confirming ID: Friend or Foe", Armor \& Mobility, November 2013, Tactical Defense Media, Inc. Silver Spring, MD, p.12-13 and Michael M. Sweeney, "Blue Force Tracking: Building A Joint Capability", U.S. Army War College, Carlisle Barracks, PA, 2008, p.3.

${ }^{16}$ During the major combat phase of Operation "Iraqi Freedom" only one soldier was killed due to direct friendly fire.On the other hand, during Operation "Desert Storm" by direct friendly fire were killed 35 soldiers, and 72 wounded.

17 Joint Battle Command-Platform (JBC-P).

${ }^{18}$ Areas, Structures, Capabilities, Organizations, People, and Events (ASCOPE).
} 
spectrum of operations, i.e. because of need that small dismounted units increase combat efficiency in all types of combat operations. It has been in troop use since November $2007 .^{19}$

TiGR breaks from the traditional hierarchical, bottom-up filtered information flow of reporting, and instead builds on the successes of direct peer-to-peer collaboration. ${ }^{20}$ Its collaborative environment provides a unique multimedia solution using graphics, high resolution imagery, line of sight tools, and a searchable database to support the full spectrum of operations. Of particular importance is its role in planning, preparations, assessments and execution of tasks. Data submission network is sufficiently flexible to respond to challenges at the tactical level. ${ }^{21}$

Good sides of TiGR system are:

- Allows an insight into the situation on the ground through a visual display unit placement in the field and at all levels of command.

- Support of all types of combat systems and units.

- Enhanced information flow between the company commanders and platoon commanders.

- Full cooperation in the field between the lower tactical units, the basic tactical units and operational centers.

- It is designed to be used around the world.

- Information distribution network is compatible with various command and control tactical network systems, which include receiving and exchanging data.

- Mapping is done using Web Mapping Service (WMS), which provides access to high-resolution graphs.

- The ability to record current operations and their storage in the database, as well as the possibility of using them for after-action analysis.

- Possibility of adjustment and adaptation of the user interface depending on the needs and personal experiences.

- To use the application you need to conduct a short-term training. Training for the use of applications takes 30 minutes due to the simplicity of the application and the previous user's knowledge. ${ }^{22}$

Unit commanders on the ground have had very positive experiences with TiGR system. ${ }^{23}$ The problems are mainly related to security issues:

- Not all of the soldiers on the battlefield have the same level of access to classified information.

- User authentication.

- Risks that involve transferring data wirelessly.

- The issue of crypto protection.

${ }^{19}$ Tactical Ground Reporting System (TiGR), Scottsdale, AZ, General Dynamics Mission Systems, visited the day: 14 March 2015, http://www.gdc4s.com/tactical-ground-reporting-system-\%28TiGR\%29.html

${ }^{20}$ Tactical Ground Reporting System (TiGR), Scottsdale, AZ, General Dynamics Mission Systems, visited the day: 14 March 2015, http://www.gdc4s.com/tactical-ground-reporting-system-\%28TiGR\%29.html

${ }^{21}$ Todd Hack Talks About Building The TiGR App, 5 September 2014, Scottsdale, AZ, General Dynamics Mission Systems, visited the day: 13 March 2015, http://thesoldiersnetwork.com/creating-TiGR/.

${ }^{22}$ Tactical Ground Reporting (TiGR) System, Scottsdale, AZ, General Dynamics Mission Systems, visited the day: 14 March 2015, http://www.gdc4s.com/Documents/Programs/TIGR\%20Handout-Final.pdf

${ }^{23}$ Cerdec's work in developing, assessing and adapting hand-held solutions and commercial applications for the battlefield, August 25, 2010, Washington, DC, Department of Defense, visited the day: 14 March 2015 , http://www.defense.gov/Blog_files/Blog_assets/20100825_anthony_transcript.pdf, p.4. 
The TiGR architecture consists of clients, mobile servers, edge servers, and core servers. ${ }^{24}$ Core servers are located in large bases with reliable facilities including good network connectivity. They are home to search information for all content created in a theater of operation. Edge servers are typically located in smaller forward operating bases. These servers provide local content and also serve as a conduit through which content is obtained from the other servers in the network. Mobile servers are placed in command vehicles which enable the constant data flow. The clients use stationary and mobile computers with browsers.

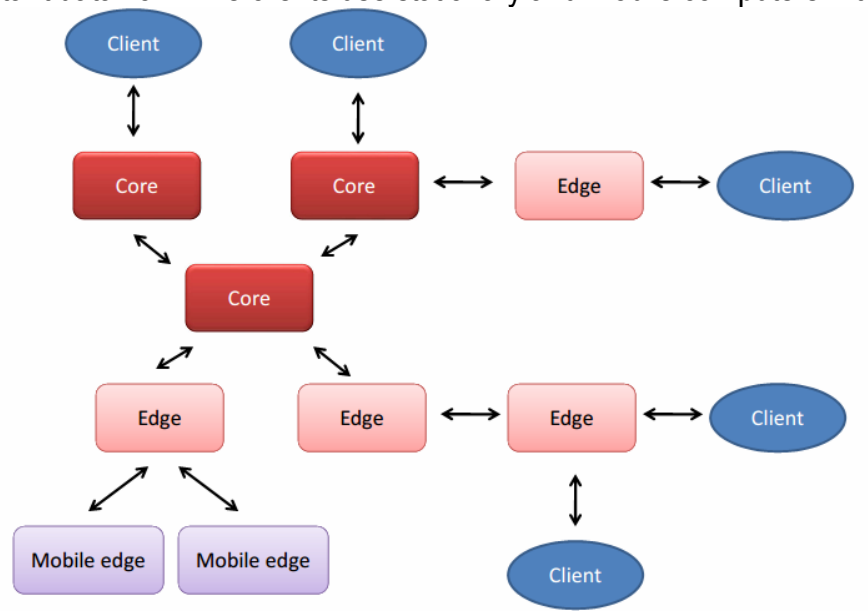

Fig. 4 - Sample TiGR logical network25

TiGR interface is based on geographic maps. The interactive display allows commanders quick overview of information related to the field, events, residents and facilities with the aim of effectively and timely disclosure of information before, during and after the execution of the task. Visualization of information with topographic maps and GPS positioning in real time provide fast and accurate view to software users.

The simple interface is based on a system of menus and tabs close to the young generation of soldiers they have on their laptops and smart phones. There are five tabs: Search, Create, Forums, Messages and Profile.

For TiGR system's users in the field, General Dynamics has developed a robust GD300 tactical computer. Through various radio and satellite systems, it connects the soldiers in the field with the command centers and allows communication at great distances. ${ }^{26,27}$ TiGR

${ }^{24}$ TIGR: The Tactical Ground Reporting System, October 2013, New York, NY, IEEE Communications Magazine, visited the day: 16 March 2015, http://cae.ittc.ku.edu/papers/TIGR.pdf, p.45.

${ }^{25}$ Joseph B. Evans and others, "TIGR: The Tactical Ground Reporting System", IEEE Communications Magazine, New York, NY, October 2013, visited the day: 16 March 2015, http://cae.ittc.ku.edu/papers/TIGR.pdf, p.47.

${ }^{26}$ General Dynamics to Deliver Prototype Equipment to Enhance Battlefield Situational Awareness for Soldiers and Marines, March 18, 2011, Scottsdale, AZ, General Dynamics Mission Systems, visited the day: 14 March 2015, http://www.gdc4s.com/news/archives-news/2011/mar-18-2011.html.

${ }^{27}$ GD300, Sunrise, FL, General Dynamics Itronix, visited the day: 14 March 2015, http://www.infotim.com/resources/files/pic/GD300.pdf 
applications with the radio AN/PRC-154 and GD300 tactical computer were delivered to $75^{\text {th }}$ Ranger Regiment, which was deployed to Afghanistan at the beginning of the 2012 th. $^{28}$

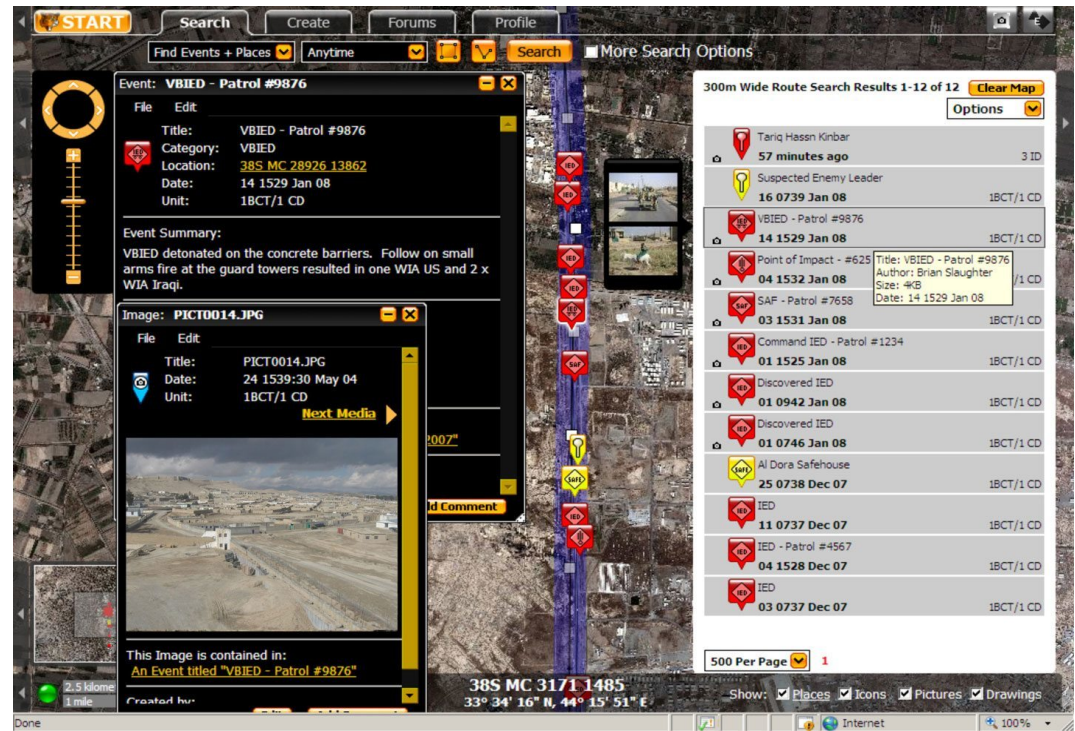

Fig. 5 - TiGR interface ${ }^{29}$

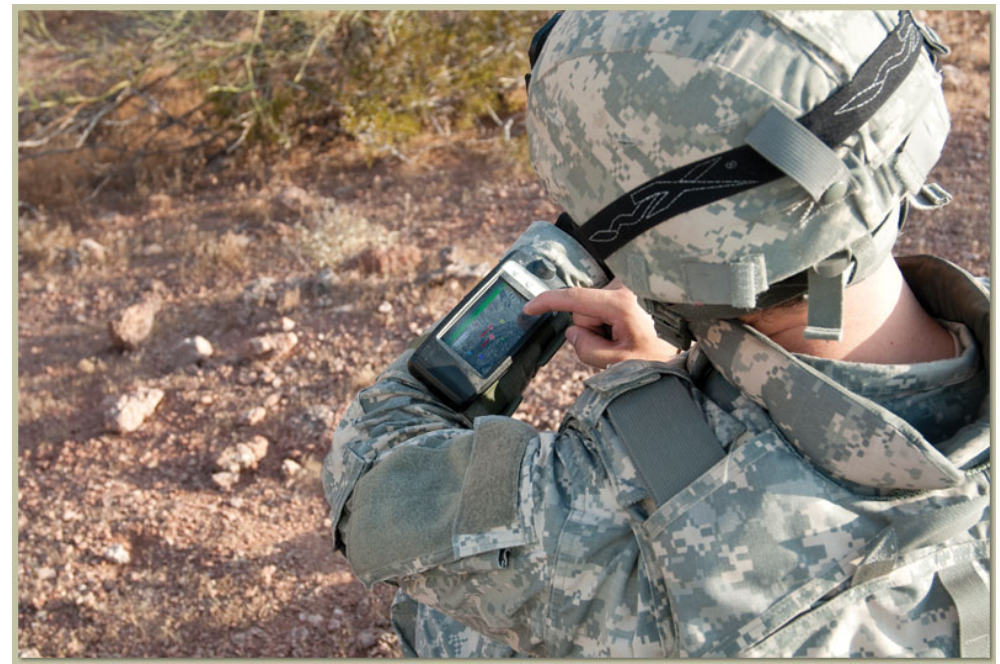

Fig. 6 - GD300 tactical computer

${ }^{28}$ General Dynamics Rifleman Radio and GD300 Go to Afghanistan with U.S. Army's 75th Ranger Regiment, visited the day: 14 March 2015, http://www.gdc4s.com/news/archives-news/2012/jan-23-2012.html

${ }^{29}$ Gardner Tim, "TIGR (Tactical Ground Reporting) Handbook", Afghanistan, 23 Dec 2010, p. 10. 


\section{GeoSuite}

GeoSuite is a multimedia system that allows data collection, reporting and sharing of information to its users. The system is designed to TiGR system, that is suited for commercial use. It is especially designed for users at lower levels of the hierarchical chain, such as police officers, lifeguards, field operatives and volunteers. It is designed for better awareness of the situation on the ground, easier cooperation and sharing of information between the users and the analysis after the execution of tasks and missions. ${ }^{30}$

GeoSuite can be installed on all devices that have Windows or Android operating systems as the basis. It assists senior staff in the planning, coordination and cooperation in the highrisk events such as political meetings, parades, sports events, convoy escorts, and so on. There are several software versions of GeoSuite, which allows its use in command centers, ${ }^{31}$ vehicles $^{32}$ or field officers. ${ }^{33}$ Mobile devices and computers equipped with software GeoSuite are connected wirelessly to a centralized secure server. It serves for the storage: information gathered by field officers, data collected through sensors and cameras, and features a complete history of information, orders and instructions of operational centers.

Main features and capabilities of GeoSuite software are:

- Provides critical information to the users on the ground;

- Allows the cooperation between the personnel on the ground, dispatchers and command centers;

- Current announcements - Service members can automatically receive text or e-mail notifications, which are classified by keyword, data, sites or other parameters;

- Information sharing - Using geo-referenced information, the service members can inform colleagues about upcoming activities;

- Cooperation - More services can receive text and e-mail updates about criminal or suspicious activities from sensors that can be customized by the user;

- Multimedia content - Pictures, video and live image transmission available with different types of cameras, motion sensors and other sources that can be saved and stored;

- Currently determine location - Using GPS, the service members can determine their location and locations of their collaborators on the ground in real time;

- Maps - Through GeoSuite they can access to geographic maps and cartographic services that are on the Internet;

- Continuous operational - Access to databases is possible when the wireless network connection or battery power temporarily disabled;

- Very suitable for the execution of tasks - from local and global;

- Training for users is carried out for 90 minutes.

30 GeoSuite, Scottsdale, AZ, General Dynamics Mission Systems, visited the day: 14 March 2015 http://www.gdc4s.com/geosuite.

${ }^{31}$ GeoSuite Command: It is the server-based software that resides within the confines of relatively stable and established operation centres.

${ }^{32}$ GeoSuite Platform: It is the vehicle software that conforms to the needs of the varying operating systems that reside within vehicle platforms.

${ }^{33}$ GeoSuite Handheld: It is the mobile software application that can be downloaded to a majority of handheld devices. As a simple application, users receive the full value and power that is GeoSuite and can interact with others in platforms or command centres. 
GeoSuite software is used by some of the police and firefighter units in the United States. Through this system, these units are associated with operational centers for emergency situations, detachment of national security and anti-terrorist information centers. In this way, the participants of the system are aware of the arrangement of the various units in the field. Also, it is possible to gain insight into the current and ended incidents by priority engagement, gain insight into the video surveillance footage set in public places and access archived photos. Perhaps most important, it allows an exchange of data between different units in the field in real time.

\section{Conclusion}

During the initial experiments with FBCB2 in 1995, location determining and command and control are drastically improved. Compared with the orders that are transmitted by radio and paper topographic maps, the transition to the new system was interpreted as a transition from black-and-white images on a live color image of the highest quality. With FBCB2 soldiers knew the exact location on the land in real time. Although they were in the desert with no roads, in the middle of a sandstorm and completely blinded, they were able to see the icon of your own vehicles moving on the digital topographic map or photograph. In the same way, they knew the position of the rest of the unit and the other friendly units without reading topographic maps, using radio communication and stopping unit to determine location and perform unit's alignment. If the intelligence staff has done a good job, then the information about the enemy was also shown on the screen. ${ }^{34}$

With the supply of the TiGR system all of mentioned benefits became available to the soldiers and leaders of the units at the end of the chain of command. A huge advantage is that the decision-makers have enough time to make decisions. Military technology is often turned into commercial flows and becomes available to civilian part of the population. There are many examples: mobile telephony, internet, global positioning systems and so on. Nowadays, this is the case with the TiGR system.

Large-scale natural disasters such as flood that has affected the countries of the river Sava basin in 2014 is proof that small states cannot resist alone to threats. Assistance of other countries, which is reflected in the sending of specialized units, is necessary. Also, the country that was hit by a natural disaster mobilizes all available resources. Command and coordination of all the above mentioned elements is difficult because of their diversity. With the introduction of the system in use, controlling and reporting would certainly increase the efficiency in the execution of tasks with the least possible involvement of forces and means. Creating an application that could be used in natural disasters does not require a lot of money especially if it was a regional project. Moreover, this application would overcome the language barrier, because it would be enabled for use of different languages in the system. This would decrease errors in the command due to a misunderstanding too. Also, the application could be used to "smart" phones and it would be

\footnotetext{
${ }^{34}$ Richard J. Dunn III, "Blue Force Tracking, The Afghanistan and Iraq Experience and Its Implications for the U.S. Army", Northrupp Grumman Mission Systems, 2005, p. 4-5.
} 
available to anybody who possess them and with data access permissions. The issue of security data during natural disasters is certainly not as significant as during the execution of combat operations. Without doubt, only units' commanders in the command system would have access to information. It is primarily due to licking data from the command system to avoid demoralization and creating panic among the population.

This digital system of command and control has become a very powerful tool in the hands of commanders. There are still no comprehensive, systematic assessment of the impact of these technologies on a decision making process. ${ }^{35}$ Therefore, the question remains: Does such a tool in the future may play a role in a decision making process which until now belonged to the human beings?

\section{Bibliography}

[1] Claire Heininger, "Friend or foe: Handheld Comms Integration", Armor \& Mobility, Silver Spring, MD, January 2011, p. 19-20.

[2] David J. Bryant and David G. Smith, "Impact of Blue Force Tracking on Combat Identification Judgments", Defense Research and Development, Toronto, Canada, February 2013.

[3] FM 6-0, "Mission Command: Command and Control of Army Forces", US Army Training and Doctrine Command, august 2003

[4] Gardner Tim, "TiGR (Tactical Ground Reporting) Handbook", Afghanistan, 23 Dec 2010.

[5] Group of authors, "Driving Technological Surprise: DARPA's Mission in a Changing World", Defense Advanced Research Projects Agency, Arlington, VA, April 2013.

[6] James L. Conatser, Vincent E. Grizio, "Force XXI Battle Command Brigade and Below-Blue Force Tracking (FBCB2-BFT)", Naval Postgraduate School, Monterey, California, December 2005.

[7] John O'Connor and Christina Bates, "Confirming ID: Friend or Foe", Armor \& Mobility, Tactical Defense Media, Inc. Silver Spring, MD, November 2013, p. 12-13.

[8] Joseph B. Evans and others, "TiGR: The Tactical Ground Reporting System", IEEE Communications Magazine, New York, NY, October 2013.

[9] Kris Osborn, "Blue force, times ten", Armor \& Mobility, Silver Spring, MD, January 2011, p. 21-22.

[10] Michael M. Sweeney, "Blue Force Tracking: Building A Joint Capability", U. S. Army War College, Carlisle Barracks, PA, 2008.

[11] Nancy Jones-Bonbrest, "Situational Awareness for a Digital Generation", Armor \& Mobility, November 2013, Tactical Defense Media, Inc. Silver Spring, MD, p. 3-4.

[12] Richard Coupland, "Broadband and the future user's experience, Emerging Technologies Forum", GDC4S, 26-27 February 2014.

[13] Richard J. Dunn III, "Blue Force Tracking, the Afghanistan and Iraq Experience and Its Implications for the U. S. Army", Northrupp Grumman Mission Systems, 2005.

\footnotetext{
${ }^{35}$ David J. Bryant and David G. Smith, "Impact of Blue Force Tracking on Combat Identification Judgments", Defence Research and Development, Toronto, Canada, February 2013, p.88-89.
} 